\title{
Deconstructing Paper-Lined Cubicles: Digital Literacy and Information Technology Resources in the Workplace
}

\author{
https://doi.org/10.3991/ijac.v12i3.11170 \\ Amanda Klassen \\ University of British Columbia, Vancouver, Canada \\ amandaleahklassen@gmail.com
}

\begin{abstract}
Drawing on examples from workplace learning, trends in digital literacy needs and information technology-based resources are examined. As many organizations look to digitize learning and knowledge base materials, some employees struggle to integrate new technologies into their work routines, resulting in a re-emergence of paper-based resources. Researchers have linked digital reading preferences and performance to digital literacy $[1,2,3]$ suggesting a need to develop advanced digital literacy training in the workplace. Further, there is evidence to suggest that learning and reading retention is lower on digital workstation devices, such as desktop computers [1]. I will argue efforts to digitize learning and knowledge base resources in the workplace needs to be supported by a strategy that demonstrates the value of new technology to employee's experience, including ongoing digital literacy training and equipping employees with information technology resources that encourage the utilization of digital learning and reading materials.
\end{abstract}

Keywords—Digital literacy, digital learning, e-learning, workplace learning

\section{Introduction}

In most organizations, there is a push to digitize learning and knowledge base resources to eliminate paper waste and centralize knowledge management. However, one walk through most offices will reveal cubicles lined in paper notes, printouts of emails, working instructions, and standard operating procedures. In some cases, resistant employees will even make their own reference binders even when their organization has phased out paper-based reference materials. Paper-based resources are problematic for most organizations, as it can be cumbersome to update and ensure secure storage of sensitive information. Further, efficient information management is a competitive advantage for organizations, which can lead to increases in productivity and customer satisfaction [4].

As a workplace educator, I have implemented many digital learning solutions and observed a variety of user adoption trends. Each technology has benefits and limitations, but none have eliminated the urge some employees have to revert to paper. In this essay, I will examine the common reasons employees revert to paper when digital solutions are readily available. These reasons are derived from workplace feedback in 
my own practice collected through a variety of methods, such as course evaluations, interviews, and feedback mechanism within technical tools. The content of this feedback is valuable, as it illuminates several themes that challenge employees from fully adopting digital learning, knowledge base, and information technology resources. Specifically, I will examine five trends: information and tool overload; difficulties searching and navigating; perceived reliability and accuracy of information; preferences for print-based materials; and effort, fear, and time to learn. Through these trends, I will argue efforts to digitize learning and knowledge base resources in the workplace need to be supported by a strategy that demonstrates the value of new technology to the employee's experience, including ongoing digital literacy training and equipping employees with devices and applications that encourage the utilization of digital learning and reading materials.

While there are many frameworks for defining digital literacy $[5,6,7,8,9]$, for this essay, digital literacy is defined broadly as "the ability to use information and communication technologies to find, understand, evaluate, create, and communicate digital information, an ability that requires both cognitive and technical skills" [10]. This definition encompasses both the technical and critical thinking aspects of selecting, using, and understanding information technology resources. While this definition can be dissected into several individual capacities, such as the framework presented by EshetAlkalai [9], for this paper a broad umbrella definition is preferred to capture themes that emerge in employee experiences with learning technologies in the workplace. As a workplace educator, I agree with Frank \& Castek suggestion that the ultimate goal of digital literacy training should be to prepare learners to select and use the best program for the problem at hand [5]. This definition recognizes that the digital literacy skills needed are dependent on the task's employees need to perform. For some employees, this may mean using search engines across various platforms, while others may need to determine whether PowerPoint, Word, or a PDF is the most appropriate application for a document they are drafting. A complex definition of digital literacy may encourage training on individual competencies and may lose sight of the workplace problem solving that is needed.

Additionally, by using a broad definition of digital literacy, it is my hope that this examination is equally valuable to front-line and professional level employees. In my practice, I have noticed similar challenges with digital adoption of learning and knowledge base resources across roles, departments, and education levels. However, it should be noted that some groups of front-line employees may experience more digital strain adopting new digital tools, particularly if job tasks require quick turnover and repetition.

\section{Trends in Workplace Feedback}

\subsection{Information and tools overload}

Employees often express that they do not use digital learning resources as doing so adds an additional tool onto their already long list of tools they need to do their jobs. 
As an example, it is not uncommon for a customer service representative to need five or more web pages, tools, and applications open at one time to perform tasks. If they need to access a knowledge base article for instructions to perform a task, it is an additional tool they would need to manage. Not only can this overload of tools create anxiety in some users, but additional tools take up precious screen landscape. While it is common for employees to be assigned two monitors, it can be hard to manage multiple tools efficiently simultaneously. Some employees express that they choose to revert to paper resources because they feel they can find the information they need quicker on printouts.

Researchers have connected tool and information overload to digital literacy $[4,11]$. Employees with lower levels of digital literacy have more difficulties integrating new technologies into their everyday lives $[4,11]$. Just as employees are overloaded with the number of tools they need to use, keeping up to date on information also presents challenges, as information often comes from multiple sources [11]. Information and tool overload can create anxiety, confusion, and misinformation among employees who are not comfortable with new technologies [4].

The non-linear nature of digital reading can also present difficulties for employees with lower levels of digital literacy. As employees open tools and digital resources, they physically construct their reading path by managing multiple programs across multiple screens. As opposed to print-based resources, this reading path need not be linear. Employees can resize, sort, and organize their screens, creating a reading path that is unique to their needs. Even without managing multiple screens and programs, researchers argue that in digital reading, the reader constructs his or her reading path [12]. In this view, the design of text on a page requires a semiotic understanding from the reader [12]. This construction is influenced by digital literacy, impacting performance on reading tasks [12]. While multiple screens have been shown to help with some tasks [1], most researchers agree that organizing and using tools efficiently is influenced by digital literacy [2, 3]. Employees may construct a reading path that suits their needs, but digital literacy impacts their effectiveness in doing so.

\subsection{Difficulties searching and navigating}

Difficulties searching and navigating digital resources is another common reason that employees do not use digital resources. Feedback of this nature varies, from employees expressing difficulties searching for specific content to employees who emphatically express that they can never find anything. As employees often use many different tools, they often complain that navigation and search options are not transferable from one program to the next. Sometimes employees develop clever workarounds to avoid using unfamiliar features or programs. For example, I have observed employees using their browser's "find" feature or developing an advanced tree structure in their browser's bookmarks to avoid navigating or searching in new programs. Some employees choose to revert to paper-based resources by making their own reference binders.

At the heart of this type of feedback is digital literacy. Employees with lower levels of digital literacy are less likely to explore new technologies [1, 2, 3]. Digital literacy 
can also impact continuance behaviour [13]. Employees with lower levels of digital literacy are more likely to discontinue use of technology, particularly if they have expectations or previous experiences of difficulties using the technology [13]. Further, researchers indicate that digital literacy impacts an individual's utilization of features that require a high amount of effort [14]. Employees with lower levels of digital literacy may be less likely to use tools if navigation or search features require too many clicks or specific search formats.

As many digital resources are intuitive and share icons and features across platforms, it can be easy to overlook the need for basic training on how to search and navigate workplace information systems. While using search engines is a part of most people's day, it is not necessarily a transferable skill [5], as different platforms have different features and some search engines require specific search term formats. As an additional challenge, tools training in the workplace is often delivered by IT professionals who overlook basic navigation and search skills or use vocabulary that is unfamiliar to employees with base digital literacy skills [11]. Such training is often disconnected from the employee's experience of the product and does not adequately prepare them for application to their everyday job tasks $[4,5,11]$. Adapting training to the needs of specific groups of employees through examples in their work environment will provide a better foundation for employees to begin using new technology in their everyday job.

In my practice, the organizations I have worked with often use Confluence as an internal wiki and knowledge-sharing tool. As this product is highly customizable and encourages user-generated content, searching and navigating can be difficult for employees just starting to use the tool, as there is no 'rule' book on how spaces and webpages within it may operate. While employees new to the product may have search skills and familiarity with web navigation, they quickly find that these skills do not transfer well into the new program and they must invest time in experiencing and experimenting with the new product.

\subsection{Perceived accuracy and reliability of information}

Another common theme is that employees do not feel they can rely on information to be up-to-date or accurate. Employees who do not trust documentation tend to verify information through managers and colleagues. This habit not only impacts employee productivity, but it can also create a time burden on managers and senior team members. In some employees who do not trust digital resources, I have noticed they rely on their memory, which can create further knowledge gaps as information changes. Like other employee groups, I have also noted these employees sometimes revert to print-based resources when they locate reliable documentation.

Evaluation of content and information sources are often considered a core digital literacy skill $[5,6,7,8,9]$. Often referred to as information literacy, the ability to evaluate information content and sources is not unique to digital information [9]. However, as employees are exposed to multiple information sources and tend to be overloaded with information, evaluation of information is an essential skill for the modern workplace $[4,5,11]$. Characteristics of the "Google generation" of employees further complicates this, as there is a tendency to value quantity over quality of information, ignore 
credibility of information sources, and a pull to adopt the first item read [11]. An emphasis on information literacy is of critical importance to organizations, as it is linked not only to productivity but also service outcomes, such as customer satisfaction [4].

Information literacy is often overlooked in basic tools training and ongoing support for employees $[4,11]$. One of the reasons for this is it bridges into the area of critical thinking, which basic digital literacy often ignores [5]. In my experience, corporate training professionals often shy away from critical thinking, as it can be difficult to gain support for longer workshops that can tackle complex competencies. To accommodate this, some researchers suggest distinguishing between basic digital literacy and digital problem-solving literacy [5]. Designing training for specific employee groups and using examples from their everyday work life can better support the development of the information literacy skills they need to perform their job [11].

Interestingly, I have noted similar informational literacy challenges in academia. As a graduate student, I have noticed some of my peers in online classes preferring to start discussion threads or message the professor when an assigned article is unavailable in the Learning Management System despite the fact all articles are available through the online course reservation system on the library's website. While it is expected that graduate students have a high level of research skills, the transfer of these skills to solve a practical problem is not as intuitive as one might assume.

\subsection{Preferences for paper-based resources}

Some employees express that they just prefer paper-based resources. Employees often point out that it can be harder to take notes, highlight, and mark digital reading resources. If you do take notes in a digital document, you need to remember to save it, which can be inconvenient and easy to forget. Some employees express that they feel they can find information quicker in print-based form, as they can highlight, sort, and mark pages for ease of use and reference at a later date.

Several studies have indicated that digital literacy is linked to reading and learning preferences, demonstrating that individuals with a lower level of digital literacy are less likely to try out new technologies and adopt digital reading $[1,2,3]$. While users with higher levels of digital literacy are more likely to try out new technologies, a majority of technically-savvy individuals still prefer print-based materials for reading $[1,2,3]$. Even digital natives prefer print-based reading materials [3].

Researchers suggest that one of the reasons most people prefer print-based reading is that the act of reading often includes other activities such as writing, doodling, and marking $[14,15]$. One study found that reading is accompanied by writing $50 \%$ of the time [14]. While some devices and applications offer annotation and highlighting features, the majority of computer-based reading devices and applications on the market do not offer features that can accommodate other activities that often occur alongside reading, such as marking or doodling. Further, studies indicate that advanced features such as annotation and highlighting are often underutilized due to the 'heavyweight' interaction involved and digital literacy skills of the user [14]. As most workplace reading is computer-based, it can be hard to re-produce a reading experience that is similar to print-based reading. Depending on the limitations of the application used for reading, 
users may even need to use additional programs to perform writing activities while reading. As an example, I have observed employees using notepad applications to take notes, while reading from web-based resources.

It would be valuable to explore the experience of paperless reading and writing technologies in the workplace. As the typical office environment is equipped with workstation friendly devices, such as laptops and monitors, there is little research on e-reading and tablets in the workplace. Tablets and convertible devices are slowly starting to emerge in business hardware solution offerings. It will be interesting to observe the impact these devices have on workplace reading and writing.

\subsection{Effort, fear, and time to learn new digital technologies}

Another common theme in feedback is that employees feel using digital resources requires more time and effort than using print-based materials. Some employees express they are scared to explore new technologies for fear they might inadvertently make a mistake or somehow break the program. Finally, many employees feel they do not have the time to learn new technologies while keeping up with the demands of their jobs. Many of these employees recognize that learning new technologies requires exploring and experiencing the technology, however, they do not feel they are provided with time during their workday to engage in the self-led training they need.

Researchers have theorized that effort impacts reading and learning retention, as some of the mental resources used during reading are deferred to performing a task, such as turning a page, scrolling, or clicking [1, 2, 3, 14]. Applications and devices that require 'heavyweight' interactions from the user tend to show a decrease in reading comprehension [14]. Hyperlinks also impact reading and learning retention, as users must unconsciously decide to not click before continuing on their reading path [3]. Tablets and e-readers have been shown to require less effort and tend to lead to better reading comprehension than computer-based reading [1, 2, 3, 14]. As most workplace reading is computer-based, the applications used for digital reading often require a lot of effort through scrolling and zooming to accommodate the computer screen.

While tablets and e-readers generally require less effort than screen reading, the application used for reading also impacts effort. For example, in my practice there is a group of employees that primarily work with iPad. Interestingly, these employees often find engaging with our internal wiki difficult, as the default view has a wide sidebar menu that obstructs almost half of the reading area of the screen. To read an article, an iPad user must scroll not only down, but also continually scroll left and right to view the full article. Similarly, e-learning with audio can be a challenge in the workplace, as employees are often not provided headphones, so they need to seek out a pair or remember to bring their personal headphones. The arrangement of desktop computers can also present issues, as in one example, computers were mounted to the back of monitors beyond the reach of most wired headphone lengths.

Time and effort expectations have also been connected to performance using new technologies $[4,13]$. Employees that feel time-pressured in their jobs are less likely to adopt new technologies and are prone to errors using unfamiliar application [4]. Perceived difficulty and time investment have also been shown to impact employee 
engagement with e-learning [13]. Employees who expect a high level of effort and time investment in e-learning are less likely to seek out and continue using e-learning [13]. Further, time and effort expectations are linked to digital literacy, as employees with lower levels of digital literacy struggle to use digital learning resources and take longer to perform learning tasks $[4,13]$.

Digital literacy also impacts employee willingness to explore new technologies. Individuals with higher digital literacy levels tend to be more willing to explore new technologies and application features, while individuals with lower levels of digital literacy tend to be uncomfortable exploring and using new technologies beyond basic navigation $[1,2,3]$. In my practice, I have noted that some employees lack confidence in their digital skills and fear that by exploring new applications they may somehow break the program. While digital literacy training could increase confidence by supporting the development of employee's digital skills, I think it is also important to create a space where employees can safely experiment. For example, educating employees that an administrator can revert changes or giving employees access to revert these changes themselves could establish a digital safe space where employees can learn through exploration.

\section{Conclusion}

Through the workplace feedback trends outlined above several overarching themes emerge. First, more support and training are needed for employees to trust, explore, and have confidence in using digital learning and reading resources. As most digital tools are considered intuitive, training often skims over basic content, such as navigation and searching. Training is often generalized for the entire organization, so little time is spent demonstrating the value and application of the new technology on employees' everyday job. Central to Knowles framework of andragogy is the assumption that adults are problem-centred learners who are more willing to engage in learning that has immediate application to their work [16]. From this perspective, effective training would include demonstrating the value of new technologies and allowing employees to experiment to solve problems in the workplace that matter to their role. Andragogy also places a priority on the experiences adult learners bring to the learning environment [16]. Adult learners in the workplace have a variety of experiences with technology. While technology is integrated into our everyday lives, many employees still struggle with digital concepts and the evaluation of content. As adult learners come from a variety of backgrounds, we cannot assume they have received sufficient digital literacy training, so training design needs to accommodate multiple levels of digital literacy. Further, it is important that organizations support ongoing digital literacy training, not just training that accompanies implementing new digital tools and systems.

Another major overarching theme is the limitations of devices and resources available to employees. Employees typically only have access to desk or workstation friendly devices, such as laptops, computers and monitors. As demonstrated throughout this essay, computer-based reading is linked to decreases in reading comprehension, as the features and applications available on computers typically require more effort $[1,2,3]$. 
Computer-based reading has also been linked to adverse health effects, such as eye fatigue and headaches $[1,2,3]$. Fatigue not only impacts efficiency and productivity but can discourage employees from using digital learning and reading materials as it causes them distress. As tablets and e-reading technology reduce effort and health effects, it is worth investigating the impacts these devices have on workplace learning and reading. Additionally, tablets with digital writing capabilities may help bridge the feature gap in digital reading by affording the writing, doodling, and note taking that often occurs alongside reading.

While ongoing training and information technology resources are critically important, we cannot understate the importance of employee experience. In my experience as a workplace educator, decisions to move away from print-based resources come from the top-down. These projects are often led by project managers with little relation to the challenges that many front-line employees face. Involving a variety of stakeholders in these projects is important, as it can diversify perspectives and experiences [11]. In addition to the involvement of stakeholders, a thorough need analysis is vital to capture critical gaps in employee skill and information technology-based resources. Further, partnering with marketing and communication departments can help sell and promote the value of new technologies to employees [11]. In my experience, demonstrating value can help with change management and minimize the message of resisters.

In the debate of paper versus digital, both research and employee experiences indicate that many people still prefer print-based resources for reading $[1,2,3]$. However, as environmental concerns and the availability of technological solutions to eliminate paper increase, the pressure to digitize the workplace is not likely to disappear. To ensure successful adoption of digital learning and reading resources in the workplace, the employee experience needs to be closely considered. Training needs to be cognizant of varying levels of digital literacy and respect that adult learners are more likely to engage with problem-centred learning. Finally, flexibility in the kinds of devices and information technology resources available to employees would encourage employees to utilize digital learning and reading materials.

\section{References}

[1] Aeschliman, C., Chase, A., Ross, B., \& Pechenkina, E, "Print Versus Digital Texts: Understanding the Experimental Research and Challenging the Dichotomies," Research in Learning Technology, vol. 25, pp. 1-12, 2017. https://doi.org/10.25304/rlt.v25.1976

[2] Myrberg, C., \& Wiberg, N., "Screen vs. Paper: What is the Difference for Reading and Learning?", Insights, vol. 28, 45-54, 2015. https://doi.org/10.1629/uksg.236

[3] Tanner, M., "Digital vs. Print: Reading Comprehension and the Future of the Book", vol. 4, pp. 1-12, 2014.

[4] Barham, L., \& Kirton, J., "Information Literacy in the Workplace," The Australian Library Journal, vol. 54, pp. 365-376, 2005. https://doi.org/10.1080/00049670.2005.10721784

[5] Castek, J., \& Frank, T., "From Digital Literacies to Digital Problem Solving: Expanding Technology-Rich Learning Opportunities for Adults", Journal of Research and Practice for Adult Literacy, Secondary, and Basic Education., vol. 6, pp. 93-106, 2017.

[6] Bawden, D. "Origins and Concepts of Digital Literacy," in Digital Literacies: Concepts, Policies and Practices, C. Lankshear \& M. Knobel (Eds.), New York: Peter Lang, 2008. 
ICELW Paper-Deconstructing Paper-Lined Cubicles: Digital Literacy and Information Technology...

[7] Gilster, P., "Digital Fusion: Defining the Intersection of Content and Communications," in Digital literacies For Learning, A. Martin \& D. Madigan (Eds.), London: Facet Publishing, pp.42-50, 2006. https://doi.org/10.29085/9781856049870.006

[8] Martin, A., "Literacies for the Digital Age," in Digital literacies For Learning, A. Martin \& D. Madigan (Eds.), London: Facet Publishing, pp. 3-25, 2006. https://doi.org/10.29085/9781856049870.003

[9] Eshet-Alkalai, Y., "Digital Literacy: A Conceptual Framework for Survival Skills in the Digital Era," Journal of Educational Multimedia and Hypermedia, vol. 13, pp. 93-106, 2004.

[10] American Library Association Office for Information Technology Policy, "Digital Literacy, Libraries and Public Policy," 2009.

[11] Hunter, I., "Digital Literacy in the Workplace," Business Information Review, vol. 35, pp. 56-69, 2018. https://doi.org/10.1177/0266382118772675

[12] Burke, A., \& Rowsell, J., "Reading By Design: Two Case Studies of Digital Reading Practices," Journal of Adolescent \& Adult Literacy, vol. 53, pp. 106-118, 2009. https://doi.org/10.1598/JAAL.53.2.2

[13] Mohammadyari, S., \& Singh, H., "Understanding the Effect of Digital Literacy on Individual Performance: The Role of Digital Literacy," Computers \& Education, vol. 82, pp. 1125, 2015. https://doi.org/10.1016/j.compedu.2014.10.025

[14] Buchanan, G., Pearson, J., \& Thimbleby, H., "Designing for Digital Reading," Synthesis Lectures on Information Concepts, Retrieval, and Services, 2014. https://doi.org/10.2200/S00539ED1V01Y201310ICR029

[15] Fortunati, L., \& Vincent, J., Sociological Insights on the Comparison of Writing/Reading on Paper with Writing/Reading Digitally," Telematics and Informatics, vol. 31, pp. 39-51, 2014. https://doi.org/10.1016/j.tele.2013.02.005

[16] Knowles, M., The Adult Learner: A Neglected Species, $3^{\text {rd }}$ ed., Houston: Gulf, 1984.

\section{Author}

Amanda Klassen is a Learning Consultant working in Public Safety in Vancouver BC. She is also a candidate for Master of Educational Technology at University of British Columbia.

This article is a revised version of a paper presented at the International Conference on E-Learning in the Workplace 2019 (ICELW 2019), held in June 2019, at Columbia University in New York, NY, USA. Article submitted 2019-07-01. Resubmitted 2019-07-24. Final acceptance 2019-07-25. Final version published as submitted by the authors. 